\title{
Article \\ Development of an Actuator for Translatory Movement by
Means of a Detented Switching Shaft Based on a Shape
Memory Alloy Wire for Repeatable Mechanical Positioning
}

Tobias Schmelter ${ }^{1, *}$, Benedict Theren ${ }^{1}$, Sebastian Fuchs ${ }^{2}$ and Bernd Kuhlenkötter ${ }^{1}$

1 Chair of Production Systems, Ruhr-University of Bochum, Universitaetsstrasse 150, 44801 Bochum, Germany; theren@lps.rub.de (B.T.); Kuhlenkoetter@lps.rub.de (B.K.)

2 MMB Maschinen, Montage \& Betriebsmitteltechnik GmbH, Am Lindenkamp 17, 42549 Velbert, Germany; sebastian.fuchs@mmb-velbert.de

* Correspondence: schmelter@lps.rub.de

check for updates

Citation: Schmelter, T.; Theren, B.; Fuchs, S.; Kuhlenkötter, B.

Development of an Actuator for Translatory Movement by Means of a Detented Switching Shaft Based on a Shape Memory Alloy Wire for Repeatable Mechanical Positioning. Crystals 2021, 11, 163. https:// doi.org/10.3390/cryst11020163

Academic Editor: Raghvendra Singh Yadav

Received: 22 December 2020

Accepted: 2 February 2021

Published: 6 February 2021

Publisher's Note: MDPI stays neutral with regard to jurisdictional claims in published maps and institutional affiliations.

Copyright: (c) 2021 by the authors. Licensee MDPI, Basel, Switzerland. This article is an open access article distributed under the terms and conditions of the Creative Commons Attribution (CC BY) license (https:// creativecommons.org/licenses/by/ $4.0 /)$.

\begin{abstract}
Actuators based on the shape memory effect have recently become more and more economically important due to the many advantages of shape memory alloys (SMAs), such as their high energy density. SMAs are usually used to control the end/maximum positions, thus the actuators always move between two positions. The repeatable control of intermediate positions has so far proven difficult, because in most cases, external sensors are necessary to determine the length of the SMA element. Additionally control strategies for SMA actuators are rather complex due to the non-linear behavior of this material. The SMA actuator presented here is able to control intermediate positions with repeatable accuracy without the need of a separate control technology. The integrated control unit is based on a mechanical principle using a shaft with a circumference groove. This groove has a height profile that turns the shafts rotation, generated by the SMA, into a translational movement. Therefore, the SMA wire generates a partial stroke at each complete activation, turning the shaft partially. With several activation cycles in a row, the stroke adds up until reaching the maximum. A further activation cycle of the wire resets the actuators stroke to its initial position. Each part of the stroke can, thereby, be controlled precisely and repeatedly within the scope of each complete cycle of the actuator. Based on an integrated ratchet, each stroke of the actuator can hold energy free.
\end{abstract}

Keywords: shape memory alloy; shape memory actuator; position control; energy free; mechanical control; repeatability

\section{Introduction}

Shape memory actuators are well known and used in several fields such as automotive, aviation, robotics and medicine. In the field of medical technology, shape memory alloys (SMAs) are primarily used in form of stents as a medical implant for keeping vessels or hollow organs open [1,2]. For several application fields, SMA actuators have drawn attention as a possible alternative to state-of-the-art actuator systems due to their high energy density and their potential for miniaturization of actuator systems [3-7]. The shape memory effect is based on a heat induced phase transformation between martensite and austenite [7]. This transformation results in a stroke of a SMA wire of $4-5 \%$ between a temperature range of 70 and $90{ }^{\circ} \mathrm{C}$ [8-11]. Alternatively, SMA springs can be used, which can achieve a higher stroke, but compensate for this with a reduced force. Due to the high energy density, its use is of great interest in the field of actuators [7,12-14]. In particular, the progressive miniaturization of many products is leading to new requirements, especially in terms of size and weight. In these cases, actuators based on SMA can replace conventional actuators such as electric motors or hydraulic systems. Those are furthermore characterized by their simple, noiseless mechanism and low power supply [14]. The resulting reduction 
in weight and installation space also makes the SMA actuator systems interesting for the aviation [15] and automotive industries [16,17]. Recently, soft robotic applications have become more and more focused upon [18-22]. For those applications, the shape memory actuator must be able to generate different strokes besides the two positions "fully activated" and "fully reset" [23-25]. Several approaches were investigated using different control schemes to solve this problem [26-31]. Further approaches investigate the energy consumption of SMA actuators activated via Joule heating in order to keep SMA actuators attractive for miniaturization [32]. The consumed energy should be low in order to meet with an increasing amount of austenite the electric resistance decreases [33]. Therefore, it is possible to determine the stroke of the SMA wire by monitoring the electrical resistance without external sensors, which is a great benefit for miniaturization. The value of the electric resistance strongly depends on several outer influences such as the geometry of the wire, the ambient temperature and the martensite/austenite ratio. The specific resistance of the martensite/austenite phase again strongly depends on the load case and the wear $[3,34,35]$. With an increased applied stress, the austenite start temperature increases as well [36], and with an increase in activation cycles, the resistance increases too [35,37]. Both effects influence each other. For this reason, position signals from, e.g., hall-sensors or laser displacements sensors are used as control variables. Those signals are less influenced by the mentioned disturbance.

In order to reduce the electrical complexity, an actuator based on SMA wires was developed that is able to hold energy free in four different positions mechanically. In the following section, first the actuator requirements are described followed by a methodical product development [38]. Further on, the prototype assembly and its validation are presented. In the last section, the results are discussed and steps to further optimize the actuator are proposed.

\section{Requirements of the Actuator}

An actuator is a component used to move something or apply forces. Therefore, physical quantities are converted [39]. Most actuators, based on SMA, convert an electrical signal into thermal energy via the Joule heating of the SMA. This thermal energy leads to a phase transformation in the NiTi wire and, thus, to the activation of the effect/contraction of the wire. This principle is also used for the actuator developed here.

Based on the resulting boundary conditions of an actuator in combination with the basics of the SMA, first preliminary considerations, regarding requirements for the actuator to be developed, could be formulated at the beginning of the development process (see Table 1). Two requirements were particularly decisive-apart from the general requirements of an actuator/SMA actuator. On the one hand, during the development, a special focus lays on the mechanical control of intermediate positions in order to generate several positions using only one wire. No external control technology should be used for this purpose. The second focus is set on the repeatability of the achieved stroke. Run-in effects or fatigue behavior of the wire should not influence the stroke. Furthermore, it is important that each position can hold energy free.

Table 1. Requirements of the shape memory alloy (SMA) actuator.

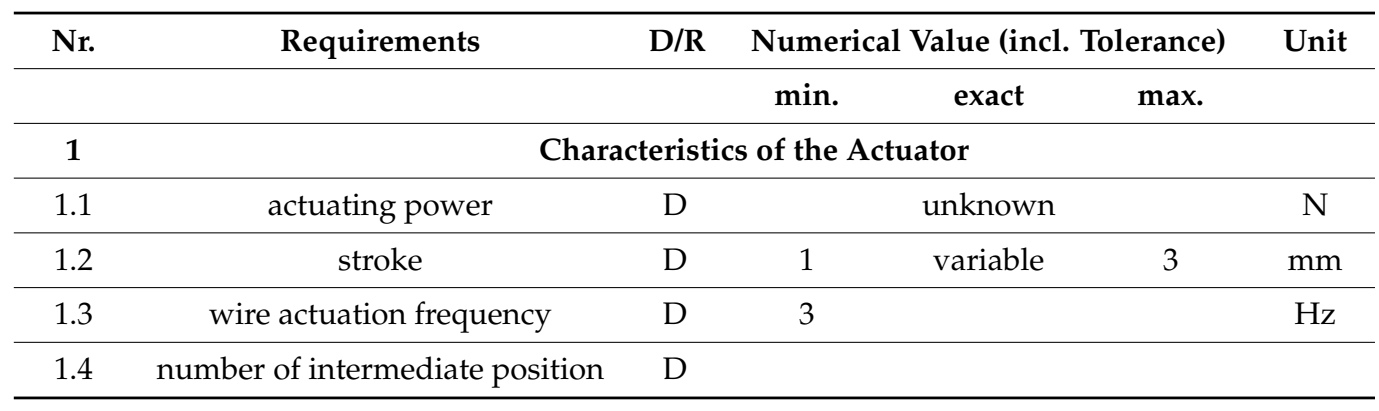


Table 1. Cont.

\begin{tabular}{|c|c|c|c|c|c|}
\hline \multirow[t]{2}{*}{ Nr. } & \multirow[t]{2}{*}{ Requirements } & \multirow[t]{2}{*}{$\mathrm{D} / \mathrm{R}$} & \multicolumn{2}{|c|}{ Numerical Value (incl. Tolerance) } & \multirow[t]{2}{*}{ Unit } \\
\hline & & & exact & max. & \\
\hline 1 & \multicolumn{5}{|c|}{ Characteristics of the Actuator } \\
\hline 1.5 & small installation space & $\mathrm{D}$ & & & \\
\hline 1.6 & low weight & $\mathrm{D}$ & & & \\
\hline 1.7 & position retainer & $\mathrm{D}$ & \multicolumn{2}{|c|}{ mechanic/energy free } & \\
\hline 1.8 & repeat accuracy & $\mathrm{D}$ & -0.1 & 0.1 & $\mathrm{~mm}$ \\
\hline 1.9 & not antagonistic & $\mathrm{R}$ & & & \\
\hline 1.10 & translational movement & $\mathrm{D}$ & & & \\
\hline 1.11 & wire length & $\mathrm{D}$ & & 300 & $\mathrm{~mm}$ \\
\hline 1.12 & voltage & $\mathrm{D}$ & & 12 & $\mathrm{~V}$ \\
\hline 1.13 & interface & $\mathrm{D}$ & & & \\
\hline 1.14 & automatically resetting & $\mathrm{D}$ & & & \\
\hline 1.15 & fast activation & $\mathrm{D}$ & & 2 & $\mathrm{~s}$ \\
\hline 1.16 & position accuracy & $\mathrm{D}$ & -0.1 & 0.1 & $\mathrm{~mm}$ \\
\hline 1.17 & long lifespan & $\mathrm{R}$ & & & \\
\hline 1.18 & low maintenance costs & $\mathrm{R}$ & & & \\
\hline 1.19 & no digital control technology & $\mathrm{D}$ & & & \\
\hline 2 & \multicolumn{4}{|c|}{ Environmental Conditions } & \\
\hline 2.1 & temperature resistance & $\mathrm{D}$ & -10 & 60 & ${ }^{\circ} \mathrm{C}$ \\
\hline 2.2 & low cross-sensitivity & $\mathrm{D}$ & & & \\
\hline
\end{tabular}

Table 1 compares the formulated requirements. Each requirement is marked with $\mathrm{D}$ (demand) or R (request). Demands have to be fulfilled; requests should be fulfilled, but are not necessary.

\section{Conceptual Design of the SMA-Based Actuator/Preliminary Considerations}

In Table 2, the definition of the requirements is finalized and the first method step of the solution area, the function level, can be developed. The created ARIZ [38] checklistadapted to SMA-in Table 2 provides further input for the formation of a function structure.

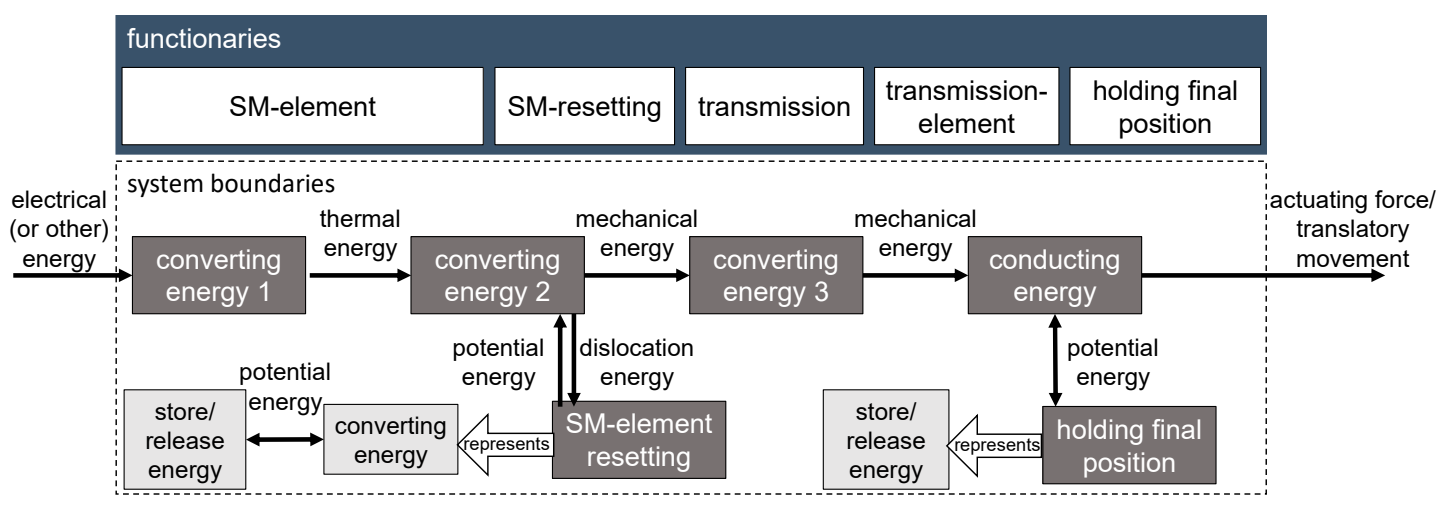

Figure 1. Function structure for the actuator to be developed. 
Table 2. SMA innovation checklist (extract).

\begin{tabular}{|c|c|c|}
\hline 4 & \multicolumn{2}{|c|}{ Analysis of the System to Be Developed } \\
\hline 4.1 & $\begin{array}{l}\text { What or which subsystem should } \\
\text { primary be improved? }\end{array}$ & None. It is a new development. \\
\hline 4.2 & $\begin{array}{l}\text { Of which elements (function carriers) } \\
\text { does the subsystem to be optimized } \\
\text { consist? }\end{array}$ & $\begin{array}{l}\text { Actuator (SMA element and reset), } \\
\text { gearbox, interface, position holder. }\end{array}$ \\
\hline 4.3 & $\begin{array}{l}\text { What is the most important function of } \\
\text { the technical system to be developed? }\end{array}$ & $\begin{array}{l}\text { Mechanical control of intermediate } \\
\text { positions, targeted positioning. }\end{array}$ \\
\hline 4.4 & $\begin{array}{l}\text { What functions are provided by the } \\
\text { individual system components? } \\
\text { (functional structure) }\end{array}$ & See Figure 1. \\
\hline 5 & \multicolumn{2}{|c|}{ Analysis of the Problem Solution } \\
\hline 5.1 & What is the ideal result to strive for? & $\begin{array}{l}\text { The actuator is adjustable in steps of a few } \\
\text { mm in its setting range and every } \\
\text { intermediate position can hold energy free. }\end{array}$ \\
\hline 5.2 & $\begin{array}{l}\text { Are there any known solutions similar to } \\
\text { the ideal result or were developed based } \\
\text { on an analogous problem? }\end{array}$ & No. \\
\hline
\end{tabular}

Based on the information about the function carriers and the main function, it is possible to determine the sub-functions, forming the main function. A logical connection of the individual sub functions results in the function structure shown in Figure 1.

The relevant function carriers are:

- Actuator (with reset option);

- Gears (to increase forces, or to convert rotation into translation);

- Mechanical control of intermediate positions;

- Interface (power transmission);

- Position holder (energy free).

A function structure was created for the analysis of the individual function levels.

In the further process, principles for fulfilling the individual blocks, such as energy conversion, were sought. Based on these principles, a morphological box was derived. Through a combination of the different functional principles, various solution principles were developed. Subsequently, selection criteria were formulated, based on the previously defined requirements. Out of the criteria, a decision matrix was set up, which evaluated the individual solution principles as objectively as possible. One principle turned out to be most promising, which was developed and optimized in detail. The results are presented in the following section.

\section{Overall System Description}

Table 3 lists all parts installed in the actuator. Except for screws, nuts, bearings and the associated deflection, all parts are only used once.

For a simplified representation, the structure of the shaft is shown first (see Figure 2). It consists of a cover plate (1), ratchet plate (2), bearing plate (3), guide groove plate (4) and the end plate (5). The plates are fixed together by a screw (24) from below and by the four switch pins (6), which are inserted into the shaft from above. By screwing the curve plate, the bearing (7) is clamped against the bearing plate for optimal power transmission. 
Table 3. Parts list of the actuator.

\begin{tabular}{ccc}
\hline Nr. & Name & Color \\
\hline 1 & cover plate & red \\
2 & ratchet plate & orange (light) \\
3 & bearing plate & blue (light) \\
4 & guide groove plate & green (light) \\
purple & black \\
5 & end plate & silver \\
6 & switch pin (ISO 8734-3 $\times 14)$ & grey (light) \\
7 & bearing (big) (SKF 6001-2Z) & grey \\
8 & pawl & orange (dark) \\
9 & pawl spring & orange (dark) \\
10 & lower case & silver \\
11 & upper case & blue (dark) \\
12 & bearing (small) (SKF 623-2Z) & turquoise \\
13 & deflection & pink \\
14 & shift fork & black \\
15 & carriage & grey \\
16 & guide pin (ISO 8734-3 $\times 10)$ & grey \\
17 & compression spring & green (dark) \\
18 & counter spring & grey (dark) \\
19 & wire & grey \\
20 & ring & silver \\
21 & interface pin & silver \\
22 & screw & silver \\
23 & nhort) (ISO 4762-M3 $\times 8)$ & silver \\
23 & screw (long) (ISO 4762-M3 $\times 12)$ & \\
24 & $($ shaft) (DIN 7991-M3 $\times 30)$ & \\
\hline
\end{tabular}
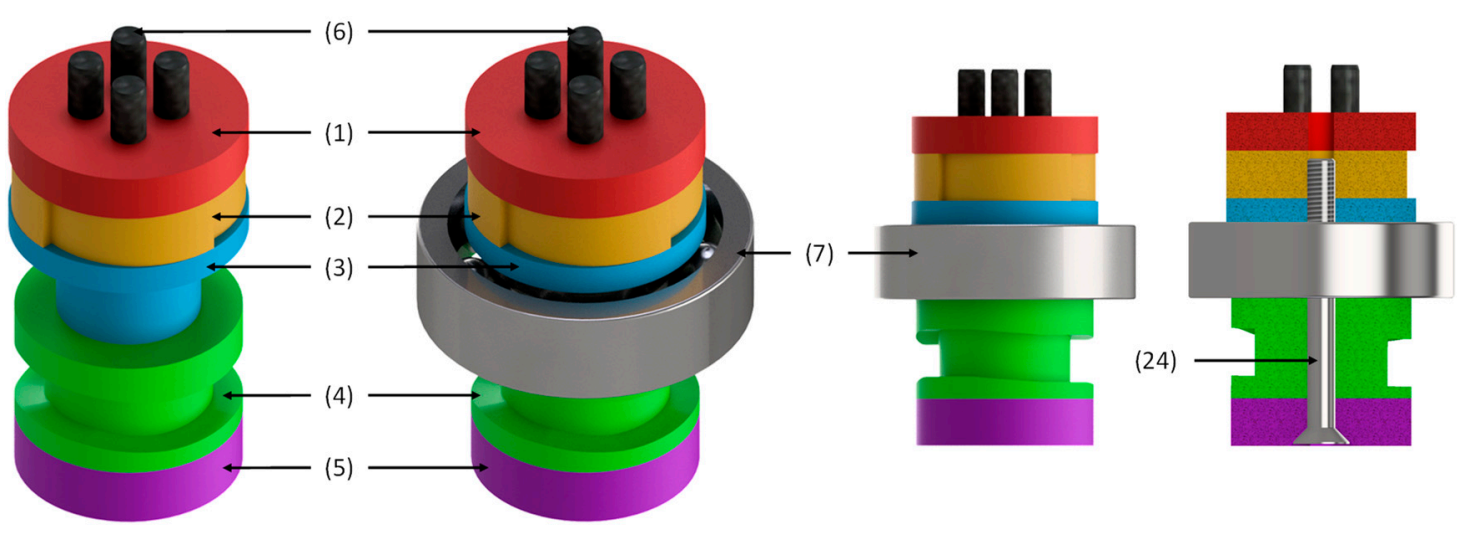

Figure 2. Actuators shaft.

The shaft is located in the center of the actuator (see Figure 3) and has four switch pins at the upper end, a ratchet in the middle and a guide groove at the lower end. It is mounted in the housing, which consists of two parts (10) (11-shown in Figure 6). The housing also contains the pawl (8), which is pressed into the ratchet by the pawl spring (9) and, thus, prevents the shaft from turning counterclockwise.

The groove of the shaft has a circumferential height profile. The unrolled course of this profile is shown in Figure 4. Based on this profile with reference to a fixed point, different heights can be set.

An interface pin (21) transmits the stroke of the groove to a ring (20). This is shown in a sectional view of the actuator in Figure 5. By rotating the shaft, four different positions (pos. 1-4) can be approached. In this design, each individual position allows a stroke of $0.577 \mathrm{~mm}$ to the previous step. After the fourth stage, the actuator generates one big downshifting stroke of $1.732 \mathrm{~mm}$, so that no explicit downshifting is necessary. The stroke can be adapted to the respective application by a simple design adaptation of the groove. 
The stroke of $0.577 \mathrm{~mm}$ selected here is, thus, only exemplary for the development and construction of the prototype. In this example, the four positions have clearly defined and repeatable stroke steps of $0,0.577,1.154$ and $1.732 \mathrm{~mm}$.

(10)

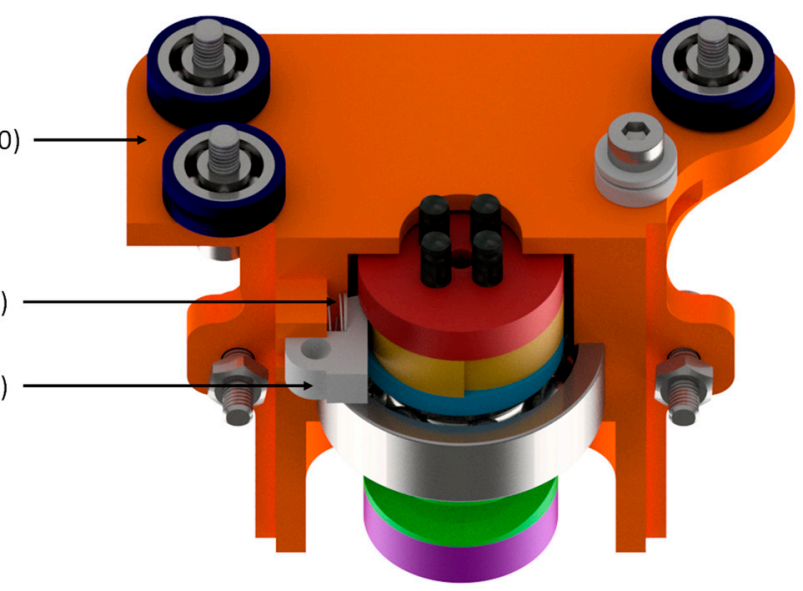

Figure 3. Shaft inside one half of the housing.

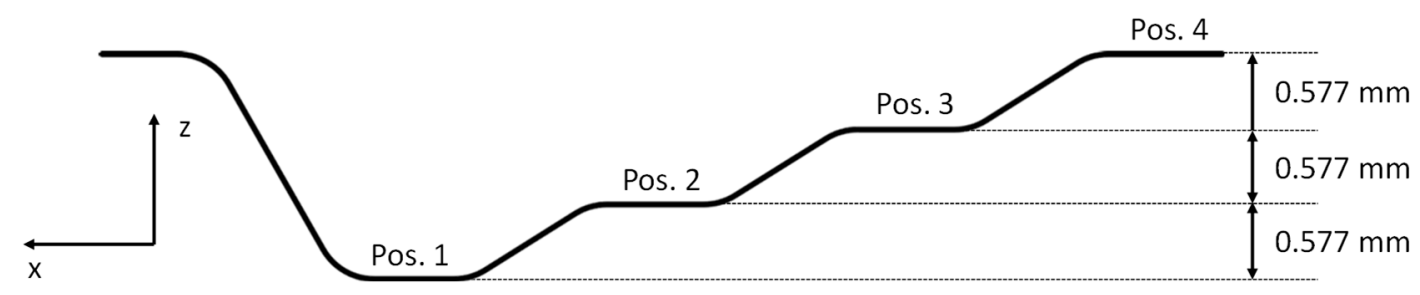

Figure 4. Unrolled height profile of the circumferential groove of the shaft.

$(14)$

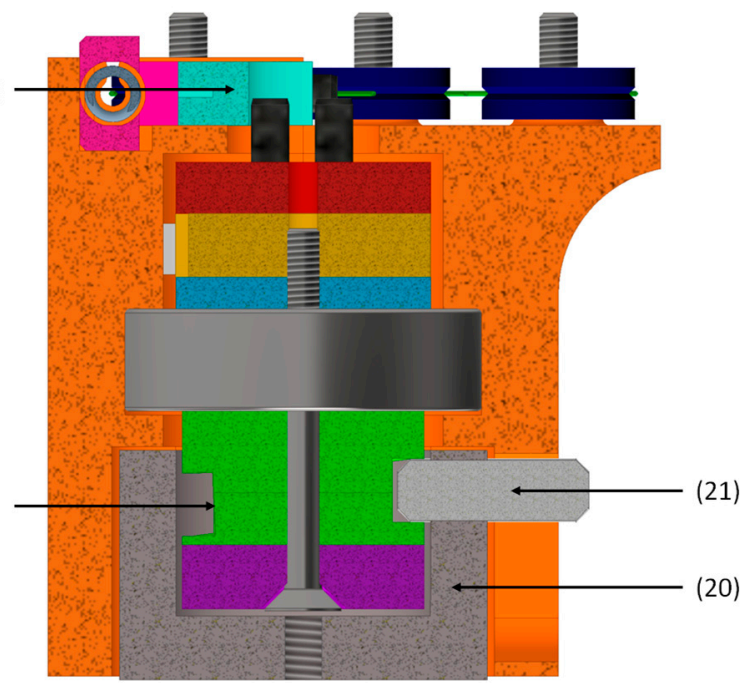

Figure 5. Actuator cut in half to show the connection between the groove (4), interface pin (21) and ring (20) and how the height profile of the circumference groove moves the ring up and down for a translational movement.

Due to its adapted shape, the ring cannot rotate, but can move axially. When turning the shaft by $90^{\circ}$ steps, the ring, including the interface pin, moves axially up by the predefined stroke of $0.577 \mathrm{~mm}$ and down again by the fourth step $\left(270-360^{\circ}\right)$. Thus, the actuator can reach four predefined heights, and due to the ratchet, the current position of the actuator is hold energy free. 
The SMA wire generates the required rotation of the shaft. If the applied voltage heats the wire (19), it activates and contracts. The shift fork (14) moves over the carriage (15) in the $X$ direction. Due to the special shape of the shift fork, one of the four shift pins is also moved, causing the shaft to rotate by $+90^{\circ}$ around its own axis as soon as the wire contracts. After a rotation of $+90^{\circ}$, a pawl engages the rotating ratchet of the shaft, preventing it from turning counterclockwise and keeping the position of the actuator energy free. These parts are shown in Figure 6.
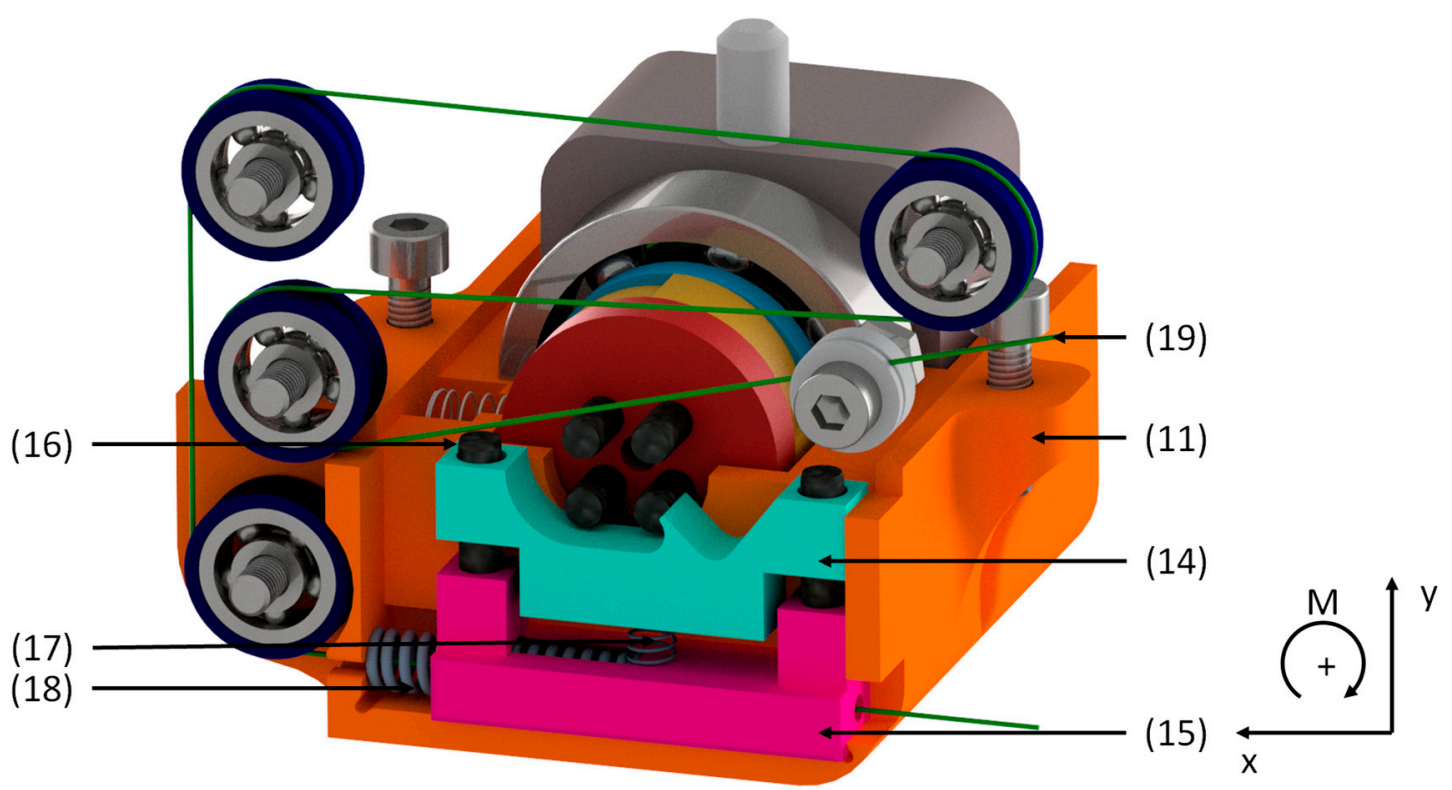

Figure 6. Fully assembled actuator with upper half of the housing (11) opened to show the shaft and ratchet (2)/pawl (8).

Releasing the wire, the counter spring (18) causes the guide element and the shift fork to return to its initial position. The shaft is held in position by the ratchet in combination with the pawl and can, therefore, not transmit any negative torque. Therefore, based on its arc shape, the shift fork slides on the previously driven shift pin and is pressed against the compression spring (17) in the negative $Y$ direction towards the carriage. Thereby, the shift fork is guided over the guide pins (16). This allows the shift fork to move back to its initial position and to restart the process.

The design of the counter-spring is rather difficult at this point, since the force required to return the carriage is primarily based on frictional forces. If a wire with a diameter of $0.3 \mathrm{~mm}$ is selected, the manufacturer specifies a recommended positioning force of $12 \mathrm{~N}$ and a maximum positioning force of $42 \mathrm{~N}$ [9]. Thus, a spring defined by the dimensions with a maximum resetting force by maximum compression of $16 \mathrm{~N}$ was chosen, which keeps the wire force sufficiently large. Furthermore, it should be noted that the complete compression of the spring does not occur and the maximum restoring force is accordingly not achieved, which preserves enough power for transmission. This must generally be taken into account when using SMA, since the spring force depends on the respective compression of the spring, which means that a constant wire force cannot be applied when using a counter spring. The data sheets of the selected counter spring are provided as Supplementary Material.

This alternation between contraction and relaxation of the wire enables the continuous, unlimited rotation of the shaft, whereby the starting position is reached again after four rotations $\left(360^{\circ}\right.$ in total).

Furthermore, the unit described above is installed in housing (see Figures 5-7), which fixes the components, aligns them to each other and conducts forces. Furthermore, the use of a lid is planned in addition. This shields the internal system from external influences and provides protection for the user. The housing is especially important for the SMA wire and 
its functionality. On the one hand, the housing protects it, and thus, it cannot be damaged by external influences. Furthermore, a sufficient force and a stroke of at least $5.4 \mathrm{~mm}$ of the SMA wire are necessary to move the shift fork far enough. When this criterion is met, the pin moves along and the catch engages so that the system can work as designed. An elongation of the wire of $2.5 \%$ is assumed for a long lifetime. Therefore, a wire length of $216 \mathrm{~mm}$ with four pulleys is calculated and chosen. The elongation is chosen so low, in order to ensure a long lifetime of the actuator wire.

(12)

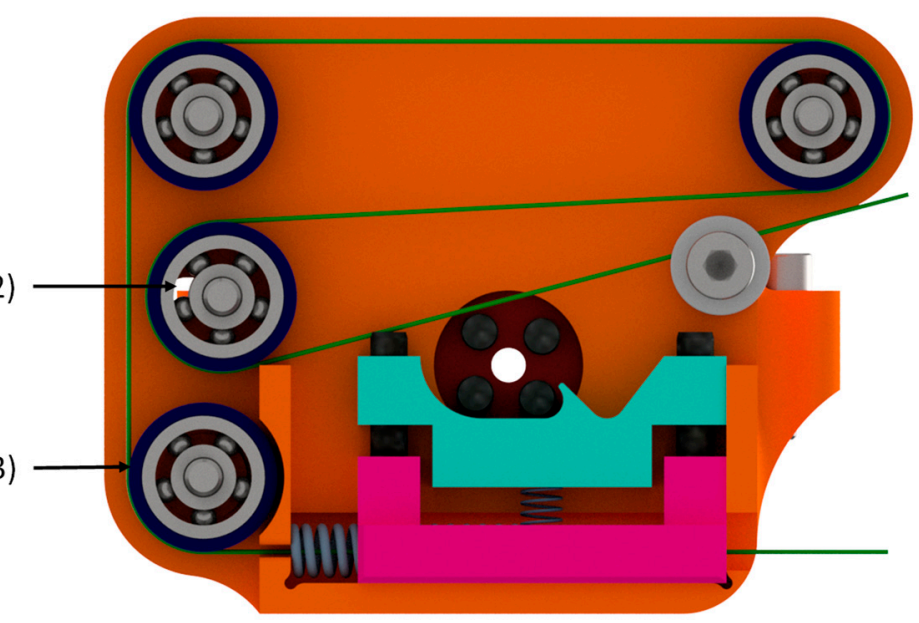

Figure 7. Top view of the actuator to show the guidance of the wire.

The wire must be accommodated in the actuator housing and is deflected several times to save space. The, therefore, needed arrangement is shown in Figure 7. In order to achieve this deflection with as little friction as possible, bearings (12) are installed at the deflection points. These are once again provided with a deflection sleeve (13) made of nonconductive material. Thus, the current cannot be dissipated during electrical activation, and an integrated guide groove prevents the wire from slipping off the bearing. In addition, the end of the wire is fixed in the housing to ensure power transmission. At the end of the carriage, the wire is crimped and is, thus, attached to it. On the other side, the wire is clamped between two metal discs by a screw. This makes it possible to retighten the wire in the prototype phase, for example if there are still run-in effects in the wire.

For further improvement and protection, an additional lid could be installed. However, since this could possibly have a negative effect on the heat dissipation and, thus, the functional properties of the wire, the use of a fan is considered instead to accelerate the cooling of the wire by forced convection. This would further improve the cycle times of the actuator. The key figures of the developed actuator are summarized in Table 4.

Figure 8 shows the exact dimensions of the actuator.
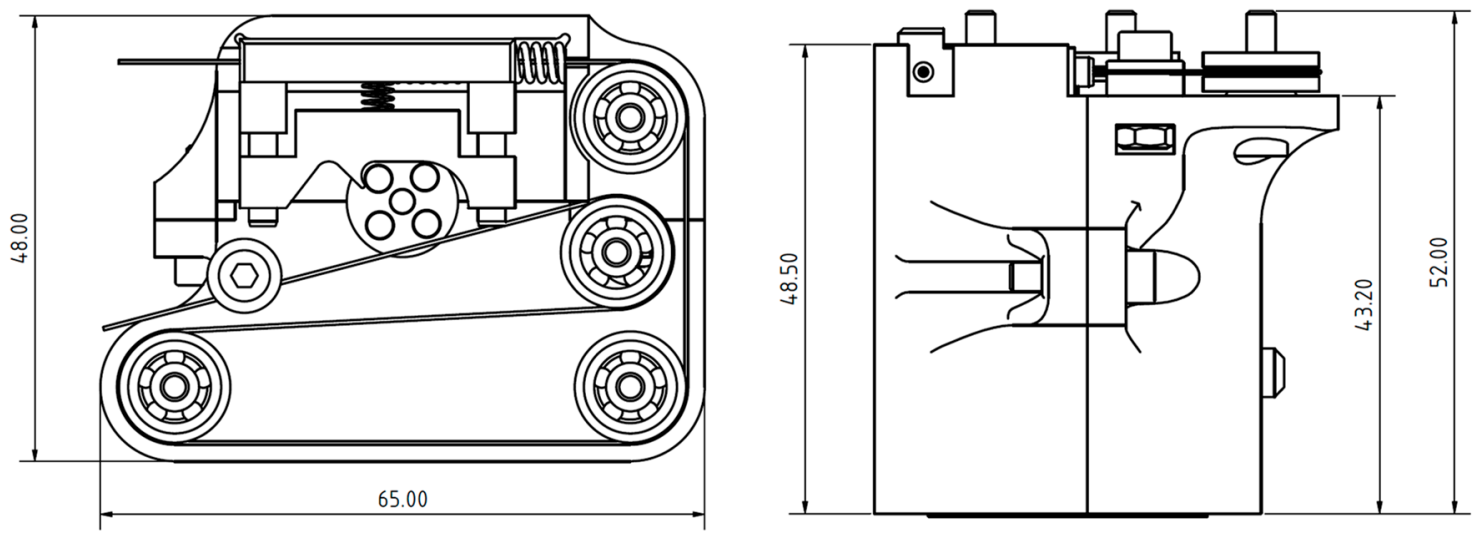

Figure 8. Dimensions of the developed actuator (all units given in $\mathrm{mm}$ ). 
Table 4. Key figures of the developed actuator.

\begin{tabular}{|c|c|c|c|c|}
\hline Specification & Variable & Unit & Formula & Value \\
\hline \multicolumn{5}{|c|}{ Initial Values } \\
\hline stroke (actuator) & $S_{w}$ & $\mathrm{~mm}$ & & 1.732 \\
\hline \multicolumn{5}{|c|}{ Assumptions and Constants } \\
\hline safety factor (for friction compensation) & $s$ & & & 1.4 \\
\hline elongation SMA wire (performance value) & $\varepsilon_{z u l}$ & & & 0.025 \\
\hline \multicolumn{5}{|c|}{ Design Parameters } \\
\hline number of switching positions & $n$ & & & 4 \\
\hline number of switching ramps & $n_{S W}$ & & & 4 \\
\hline circumference of shaft & $U_{S C}$ & $\mathrm{~mm}$ & & 31.42 \\
\hline wire diameter & $D_{\text {wire }}$ & $\mathrm{m}$ & & $3.53 \times 10^{-4}$ \\
\hline lever length trigger pin & $L$ & $\mathrm{~m}$ & & $3.536 \times 10^{-3}$ \\
\hline stroke SMA-wire & $S_{D}$ & $\mathrm{~m}$ & & 5.4 \\
\hline recommended wire force (data sheet) & $F_{\max }$ & $\mathrm{N}$ & & 33 \\
\hline maximum spring force return spring & $F_{R}$ & $\mathrm{~N}$ & & 41 \\
\hline maximum spring force pawl & $F_{\text {pawl }}$ & $\mathrm{N}$ & & 3.03 \\
\hline maximum spring force carriage & $F_{\text {carriage }}$ & $\mathrm{N}$ & & 1.49 \\
\hline maximum gradient groove & $\alpha_{\max }$ & $\circ$ & read out of the CAD file & 12.44 \\
\hline \multicolumn{5}{|c|}{ Calculations } \\
\hline required wire length & $L_{\text {ReqWire }}$ & $\mathrm{m}$ & $L_{\text {ReqWire }}=S_{D} / \varepsilon_{z u l}$ & 0.216 \\
\hline stroke of the actuator per switching operation & $H$ & $\mathrm{~mm}$ & $H=S_{w} / n-1$ & 0.577 \\
\hline switching ramp length & $L_{S R}$ & $\mathrm{~mm}$ & $L_{S R}=U_{S C} /\left(n+n_{S W}\right)$ & 7.854 \\
\hline
\end{tabular}

An initial rough representation of a mechanical replacement model is intended to clarify the functionalities once again. Thereby, forces are also plotted. This model shows the course of the forces and, especially for future optimization of the actuator, the friction forces. These can point out possible improvements in terms of force transmission. The replacement model is displayed in Figures 9-12.
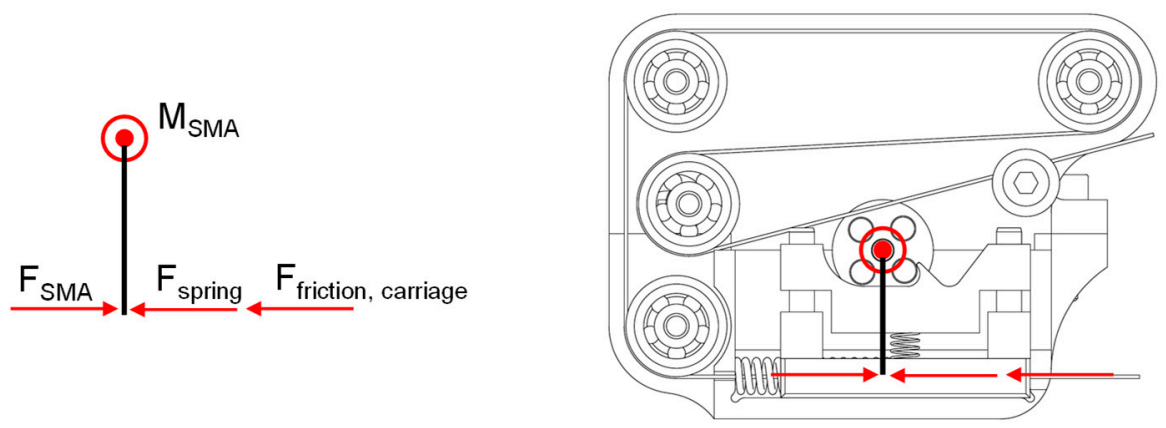

Figure 9. Conversion of the wire force into a moment.

Figure 9 shows how the force of the wire is converted into a moment. The force of the wire acts against the compression spring and must overcome the friction that occurs between the carriage and the housing.

The force path through the shaft is shown in Figure 10. Incoming is the moment generated by the SMA wire. Furthermore, the forces in the $\mathrm{X}, \mathrm{Y}$ and $\mathrm{Z}$ directions are derived through the bearing, whereby only the moment is forwarded. The moment of the shaft is decomposed into forces by the circumferential groove. For simplification, the radius required for this is assumed as the mean value of the inner and outer radius of the groove. 

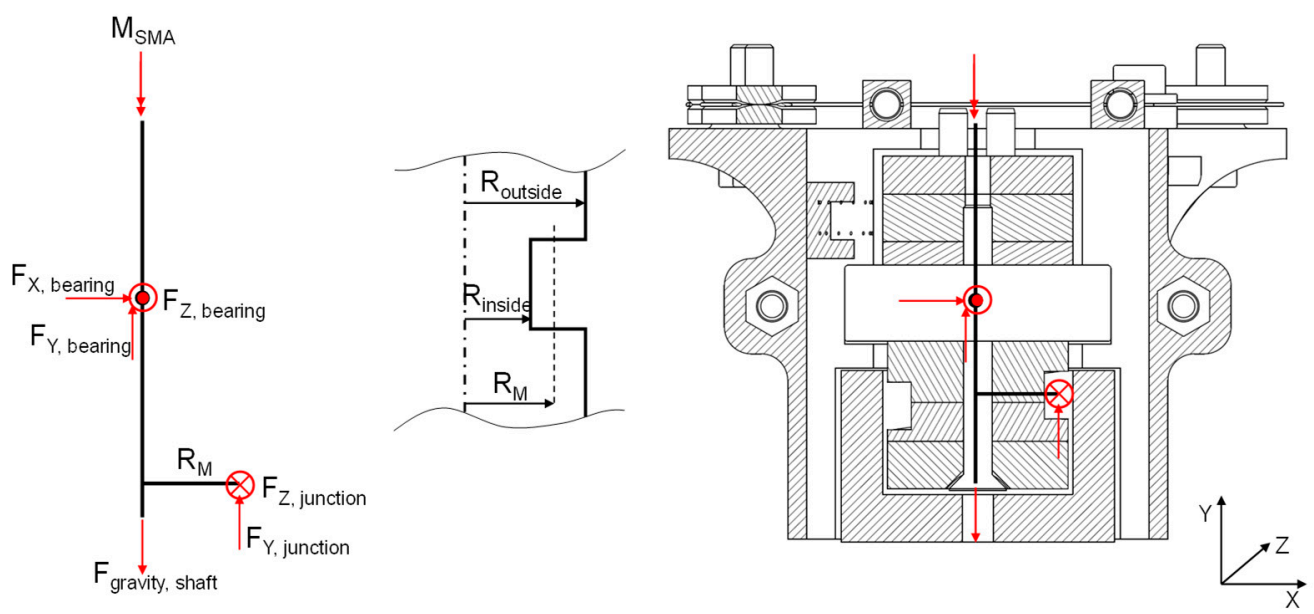

Figure 10. Transmission via the shaft and determination of the for calculations required radius (mean value of inner and outer radius).

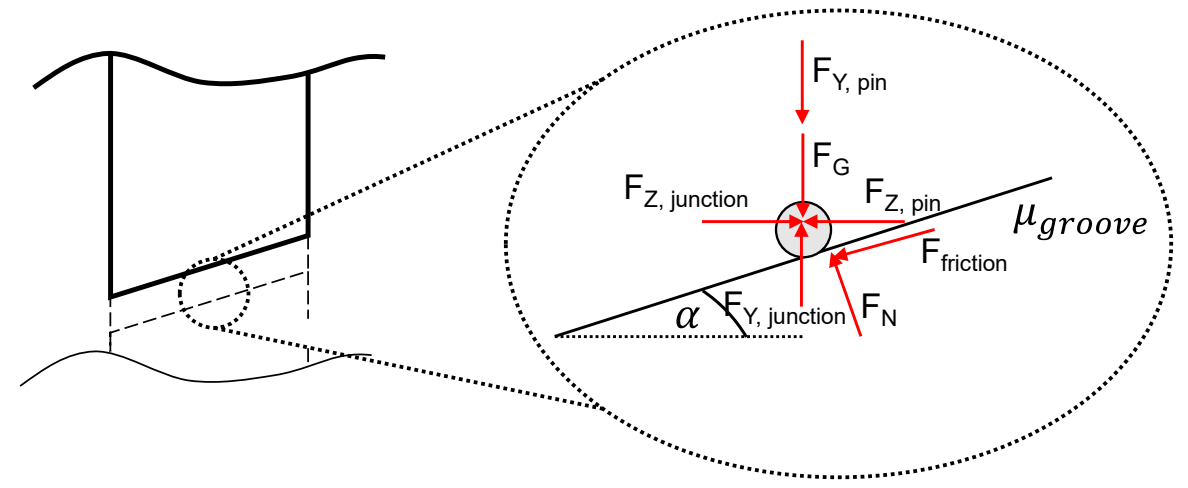

Figure 11. Contact surface of the junction pin and the inclined plane of the circumferential groove.
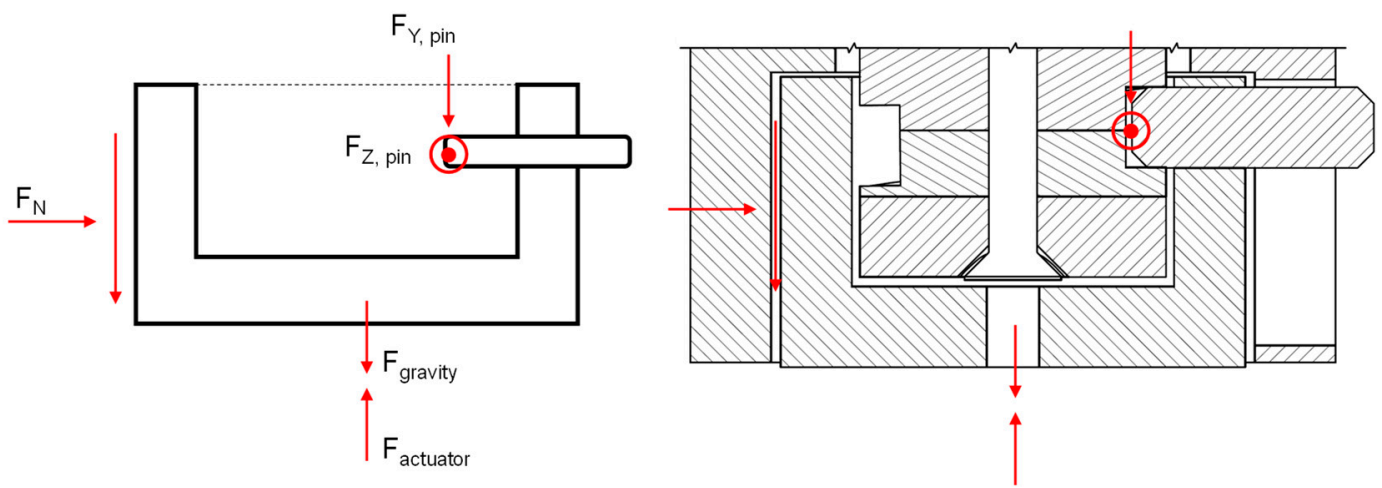

Figure 12. Generation of the force at the transmission element and, thus, the resulting actuator force.

The special complexity and, thus, a special focus has to be set on the transmission of the forces from the circumferential groove to the transmission pin, which slides on the inclined plane of the groove. There, the friction between the plane and the pin, as well as the weight force acting through the pin and ring, must also be taken into account. This relationship is illustrated in Figure 11.

The junction pins force is then transmitted to the ring, which generates the force and stroke of the actuator. Again, friction between the housing and the ring must be taken into account, whereby the transmitted force in the $\mathrm{X}$ direction can be assumed as the normal force for the friction (see Figure 12). 


\section{Assembly/Prototype}

The prototype was fabricated using additive manufacturing/fused deposition modelling (FDM). The shaft was assembled from the various components and afterwards inserted into the lower side of the housing. After inserting the pawl and associated spring, the housing was closed. The upper and lower half of the housing were fixed using screws and nuts. The assembly of the small bearings for deflection of the wire were also mounted using screws and nuts. Thereby, the bearings are clamped against the actuator housing. The integrated wire is pre-cycled to prevent the negative effects of the run-in effect. For this purpose, the wire with a diameter of $0.353 \mathrm{~mm}$ was activated over a period of 200 cycles. The activation was carried out electrically with a constant voltage of $6.8 \mathrm{~V}$, a duration of $2 \mathrm{~s}$ and a cooling time of $30 \mathrm{~s}$. During this process, a mechanical tension of $475 \mathrm{MPa}$ was applied to the wire. A high mechanical tension was chosen, because due to high manufacturing tolerances of the prototype, a lot of friction occurs, and therefore, the wire has to apply a very high force. This force can be reduced in the future by eliminating as much friction as possible. The parameters were further determined in previous long-term tests of the wire, and thereby, it could be demonstrated that the run-in effect is largely completed after 200 cycles.

After pre-cycling, one end of the wire was crimped. Then, the wire was threaded through the carriage and wrapped around the deflections. The crimp remains attached to the carriage and, thus, prevents the wire to slip through. Finally, the wire was tensioned and tightened with a screw between two washers. The finished prototype and assembly process are shown in Figure 13.
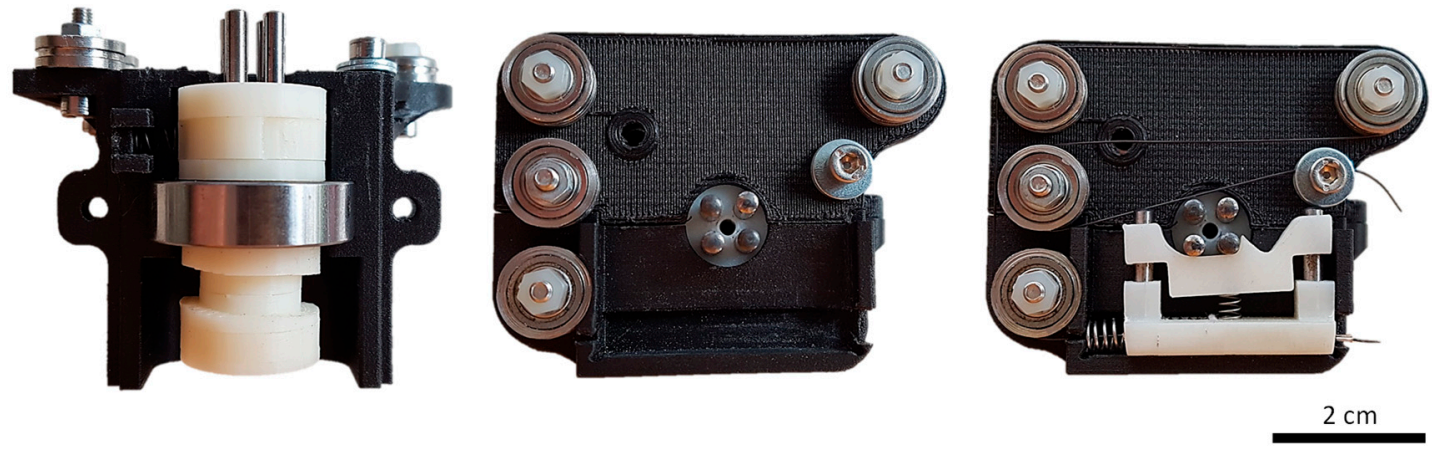

Figure 13. Assembly steps of the additive manufactured prototype.

Videos of the functionality of the prototype are available as Supplementary Material. Video 1 shows the top view of the actuator and, thus, how the rotation is generated, as well as how the shift fork and carriage return to the starting position. Video 2, on the other hand, shows the resulting stroke at the ring/interface pin. Both videos are in real time, and a fan was used for faster cooling by forced convection.

The prototype will be further evaluated in course of the project.

\section{Evaluation}

To evaluate the concept, several activation cycles were carried out using the prototype. The corresponding parameters are given in Table 5. During the test, the resulting stroke of the ring, as well as the electrical voltage and current, were measured. A determination of the applied force of the actuator is not yet useful for the prototype, since the result strongly impairs inaccuracies and roughness due to the manufacturing process (FDM). The actuator force can be optimized and adapted using a wire with a larger diameter.

Figure 14 displays the stroke and the voltage of one test series. It shows that the voltage (red curve) is kept constant during activation. 
Table 5. Parameters used for the wire and activation of the prototype actuator.

\begin{tabular}{ccc}
\hline Parameters & Value & Unit \\
\hline diameter wire & $0.353 \mathrm{~mm}$ & $\mathrm{~mm}$ \\
wire manufacturer & SAES Getters & - \\
alloy & SmartFlex SF90 & - \\
$\mathrm{A}_{\mathrm{s}}$ & $>80$ & ${ }^{\circ} \mathrm{C}$ \\
voltage & 6.8 & $\mathrm{~V}$ \\
activation time & 2 & $\mathrm{~s}$ \\
cooling duration & 16 & $\mathrm{~s}$ \\
cycles & 10 & - \\
\hline
\end{tabular}

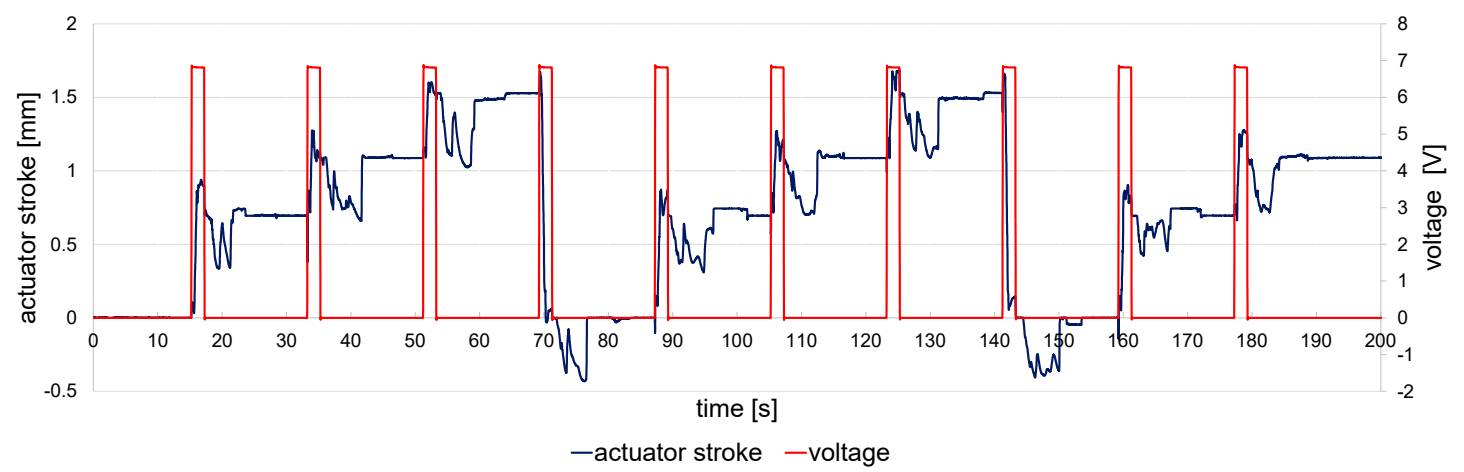

Figure 14. Applied electrical voltage and resulting generated stroke of the prototype actuator plotted over time for 10 cycles.

The four different positions controlled by the actuator are clearly visible. It can also be seen that the respective position is kept energy free. During activation, the actuator overshoots the required stroke. This is due to the design and manufacturing of the pawl/latch. The shaft always has to overturn a little bit for the pawl to grip properly.

The fluctuations of the stroke, visible at the beginning of the cooling phase, can be traced back to the manufacturing inaccuracies of the prototype. On completion of the activation, the wire begins cooling down, and the transformation into the martensite phase starts. During this process, the wire elongates again, and the return spring pushes the carriage back to its initial position. The shift fork slides on the guiding pins, with the carriage pressing against one switching pin of the shaft. This happens against the original direction of the shafts rotation and is shown in Figure 15(1). The high friction between the switching pin and shift fork $(2,3)$ - due to inaccurate manufacturing tolerances and the manufacturing process of additive manufacturing-leads to a transmission of the force instead of the planned slipping. Due to the manufacturing process and a manual optimization (e.g., filing, drilling out, etc.) with high tolerances, the slackness in the ratchet of the shaft becomes obvious. The shaft turns back a small amount and is only held in the planned position when the shift fork has returned to its original position (4).

(1)

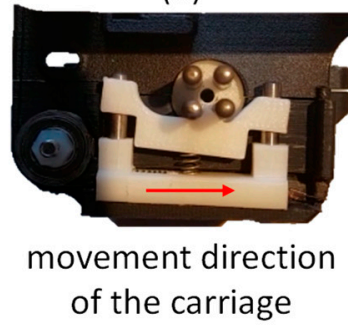

(2)

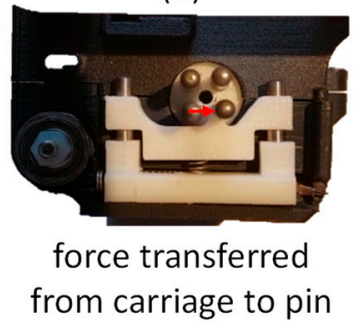

(3)

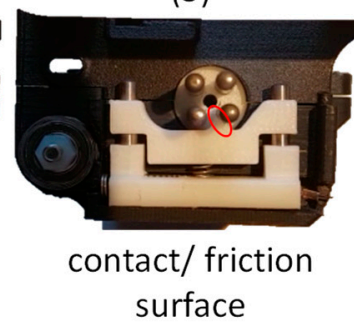

(4)

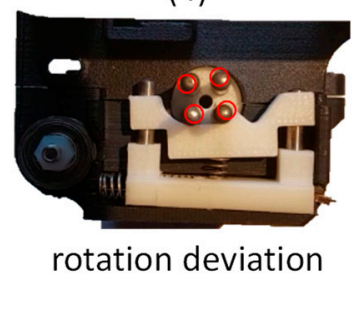

Figure 15. Representation of the sources of error during the resetting of the shift fork and the carriage generated by high roughness and inaccurate tolerances/slackness. 
Furthermore, Figure 15(1,4) shows a tilting of the shift fork caused by the counterforce of the pin. This tilting is also due to the manufacturing tolerances in the production process of the prototype, or more precisely, to excessively large diameters of the guide of the shift fork. By adjusting the tolerances so that the guide pins just fit through the guides provided for them in the shift fork, tilting of the shift fork will be prevented.

Figure 16 shows the two positions of the pins as a result of the high tolerances during resetting the carriage. This leads to the variations of the stroke. However, the movement of the pins alone does not cause such a large reset but is merely the trigger of the effect. The whole effect is intensified by slackness in the circumferential groove and an imperfect guidance of the ring.

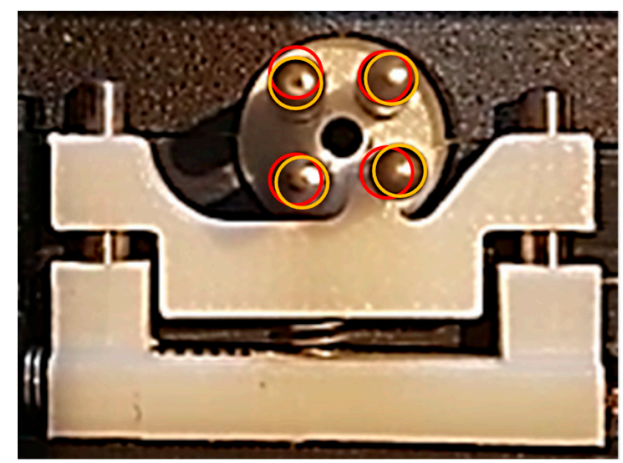

Figure 16. Clarification of the different positions of the pins while resetting; red: end position/position, as it should be; yellow: actual position as it is taken during resetting.

However, professional manufacturing of the actuator with low tolerances can eliminate these fluctuations. To visualize this, the wire was removed and the shaft was turned by hand. In doing so, the stroke of the actuator was recorded again. The results are shown in Figure 17.

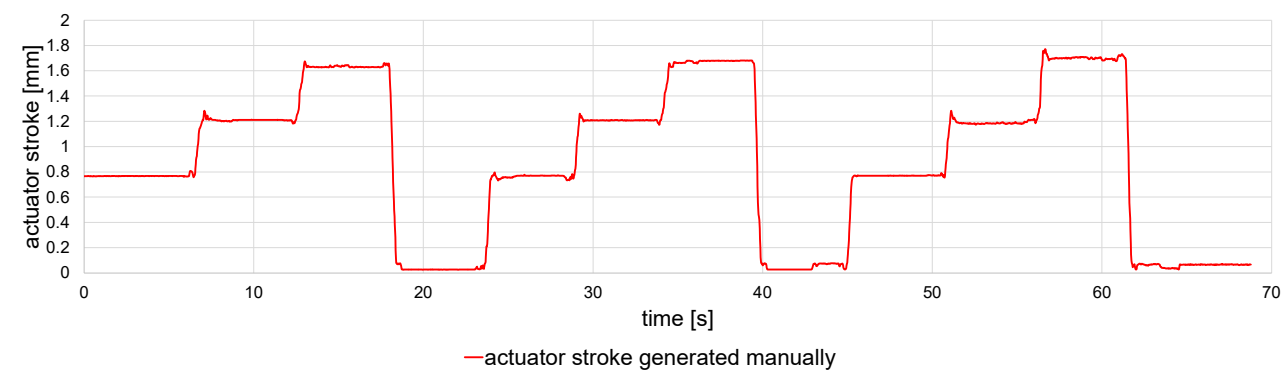

Figure 17. Stroke generated manually without using the SMA wire for activation.

It becomes apparent that the high fluctuations seen in Figure 14 are no longer present and could successfully be reduced. Only the small overshoot at the beginning remains unchanged, because the pawl still has to engage to hold the position. Resulting in an error of the linear movement of $+/-0.1 \mathrm{~mm}$ derived from Figure 17. Due to the manufacturing process, the deviation of the prototypes stroke can still vary compared to the development requirements. In principle, however, the required functionality could be validated.

\section{Conclusion and Outlook}

The developed actuator is able to control four different positions with repeatable accuracy and can hold these energies free. The four positions are generated by a single SMA wire, which is activated several times. No additional control/regulation unit is required, which would again increase the cost, weight and dimensions of the actuator. Controlling the intermediate positions is possible based on a mechanical principle. The actuator can be used to replace linear actuators with small stroke lengths. For example, 
it could be used as a mechanism to open, close and control intermediate diameters of flow units. Compared to conventional actuators, it is particularly important to emphasize that there is no electromagnetic interference with the environment.

By manufacturing a prototype, the effect was validated, and it was proven that the required stroke of the actuator can be approached with repeatable accuracy. In order to achieve the required demands such as switching frequency, a fan should be used. Any deviations that occur are due to the production method (FDM) of the prototype, since the inaccuracies/roughness of the material was already noticeable during assembly, leading to higher friction. In addition, some parts had to be optimized, since the manufacturing data are designed for a more precise manufacturing process. Using additive manufacturingespecially FDM - the components usually get a little bit bigger than planned and the optimization with files by hand increased the deviation from the required size, leading to slackness.

At this point, it is useful to draw a first comparison to a conventional actuator, since now all system properties are known, at least theoretically. The overall actuator has relatively similar dimensions to a conventional stepper motor (see Figure 18).

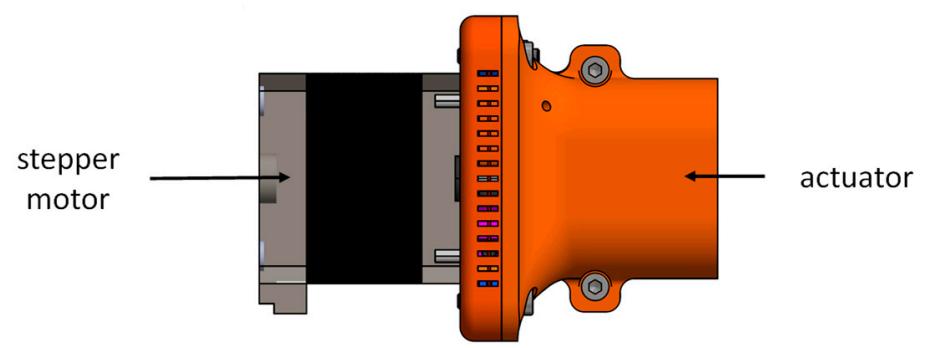

Figure 18. Actuator next to a stepper motor for size comparison.

The actuator designed here, therefore, offers advantages, especially in terms of the weight, because no magnets or copper coils are necessary. Therefore, there is also no electromagnetic influence on the environment.

Compared to other SMA actuators, it offers in particular the advantage that intermediate positions can be controlled and held by a mechanical control. Previous controls for positioning intermediate positions are not as reliable as the mechanical control developed here. In particular, the speed controlling the positions is, at two seconds, much faster than the systems that use an external control unit. Furthermore, the activation time of two seconds can easily be reduced by increasing the applied voltage. However, this may involve a reduction in service life of the wire and, thus, has to be investigated further.

In further sales, it is purposeful to manufacture the actuator-especially the circumferential groove and the slides-of metallic materials. This reduces the friction and the manufacturing tolerances enormously, and the actuator can better conduct the force of the wire. In addition, a small amount of lubrication can be used to further eliminate the friction factor. This also compensates the problem of a fluctuating stroke, as it is shown using the prototype. A targeted combination of materials keeps the weight of the actuator low, but the components have specifically significant properties such as low wear and low friction. This ensures a long service life and perfect functionality. The tolerances of the individual components can also be adjusted as a result.

An additional induction sensor could-if desired-validate the actuator's operation during use. By inserting two small magnets at opposite positions $\left(180^{\circ}\right.$ offset $)$ at the switching shaft, an inductive sensor's signal changes with each rotation $\left(90^{\circ}\right)$ of the shaft. Thereby, the functionality of the actuator is continuously confirmed, since the rotation is accompanied by the linear change in the stroke.

By a simple constructional adaptation of the circumferential slope of the groove, the actuator can be adapted to various applications. This way, the actuators stroke required for the respective application can be generated. Furthermore, an additional optimization 
of the power transfer from rotational to translational energy is considered. The actuating force can also be adapted and optimized by adjusting the diameter of the SMA wire and the electrical parameters.

Following these optimizations, a complete mechanical model can be developed to present the direct relationships of wire force and stroke to the actuator force and stroke, even considering the friction.

The performance of long-time tests will also provide insight into the service life expectations of the actuator and identify possible weak points. In this context, the deflection of the wire and its influence on the service life or force transmission can be further investigated as well. Friction could occur due to the contact area, temperature changes could occur due to a change in convection based on the contact area, and hot spots could occur in the wire due to bending of the wire. This can be combined with temperature tests to evaluate the electrical parameters for different operating temperatures between -10 and $60{ }^{\circ} \mathrm{C}$.

Supplementary Materials: The following are available online at https:/ / www.mdpi.com/2073-435 2/11/2/163/s1, Document S1: data sheet compression spring d-080b-04, Video S1: shift fork, Video S2: stroke.

Author Contributions: Conceptualization, B.T. and T.S.; validation, T.S.; resources, B.K. and S.F.; writing-original draft preparation, T.S.; writing-review and editing, B.K. and B.T.; visualization, T.S.; supervision, B.K.; project administration, B.K.; funding acquisition, B.K. and B.T. All authors have read and agreed to the published version of the manuscript.

Funding: The authors acknowledge the funding of the VarioDüse project by the Federal Ministry for Economic Affairs and Energy, grant number ZF4060730SU9. Additionally, the authors acknowledge support by the Open Access Publication Funds of the Ruhr University Bochum.

Institutional Review Board Statement: Not applicable.

Informed Consent Statement: Not applicable.

Data Availability Statement: No new data were created or analyzed in this study. Data sharing is not applicable to this article.

Conflicts of Interest: The authors declare no conflict of interest.

\section{References}

1. Ansari:, M.; Golzar, M.; Baghani, M.; Taghavimehr, M.; Abbasi Shirsavar, M.; Yahyavi, M. An experimental investigation on shape memory polymer and metallic stents under bending and radial compression. Eng. Res. Express 2020, 2, 45012. [CrossRef]

2. Shape Memory Alloy Engineering. For Aerospace, Structural and Biomedical Applications; Butterworth-Heinemann: Oxford, UK, 2015; ISBN 978-0-08-099920-3.

3. Mohd Jani, J.; Leary, M.; Subic, A.; Gibson, M.A. A review of shape memory alloy research, applications and opportunities. Mater. Des. (1980-2015) 2014, 56, 1078-1113. [CrossRef]

4. Janocha, H. Adaptronics and Smart Structures. Basics, Materials, Design, and Applications; 2. Aufl.; Springer: Berlin/Heidelberg, Germany, 2007; ISBN 978-3-540-71965-6.

5. Butera, F.; Miyazaki, S. Recent Development of Shape Memory Alloys and Engineering Actuator Application. Actuator 2010, 12, 206-211.

6. Mertmann, M. Fatigue in Nitinol Actuators. Actuator 2006, 10, 461-466.

7. Dimitris, C. Lagoudas. Shape Memory Alloys; Springer: Boston, MA, USA, 2008; ISBN 978-0-387-47684-1.

8. SAES Getters Group. SmartFlex Brochure. Available online: https://www.saesgetters.com/sites/default/files/SmartFlex\%20 Brochure_2.pdf (accessed on 10 December 2020).

9. SAES Getters Group. SmartFlex Wire \& Spring Datasheet. Available online: https://www.saesgetters.com/sites/default/files/ SmartFlex\%20Wire\%20\&\%20Spring\%20datasheets_0.pdf (accessed on 10 December 2020).

10. DYNALLOY, Inc. Technical Characteristics of Actuator Wires: FLEXINOL. Available online: https://www.dynalloy.com/pdfs/ TCF1140.pdf (accessed on 10 December 2020).

11. Ingpuls GmbH. Forgedächtnislegierungen. Available online: https://ingpuls.de/images/download/produktkatalog_ip_de.pdf (accessed on 10 December 2020).

12. Reynaerts, D.; van Brussel, H. Design aspects of shape memory actuators. Mechatronics 1998, 8, 635-656. [CrossRef]

13. Huang, W. On the selection of shape memory alloys for actuators. Mater. Des. (1980-2015) 2002, 23, 11-19. [CrossRef] 
14. Langbein, S.; Czechowicz, A. Konstruktionspraxis Formgedächtnistechnik; Springer Fachmedien Wiesbaden: Wiesbaden, Germany, 2013; ISBN 978-3-8348-1957-4.

15. Hartl, D.J.; Lagoudas, D.C. Aerospace applications of shape memory alloys. Proc. Inst. Mech. Eng. Part G J. Aerosp. Eng. 2007, 221, 535-552. [CrossRef]

16. Stoeckel, D. Shape memory actuators for automotive applications. Mater. Des. (1980-2015) 1990, 11, 302-307. [CrossRef]

17. Fraunhofer, I.W.U. Neuartige Aktoren für Industrie, Medizintechnik und Automobilbau. Elektron. Elektromechanik 2012, November, 64-65.

18. Liu, M.; Hao, L.; Zhang, W.; Zhao, Z. A novel design of shape-memory alloy-based soft robotic gripper with variable stiffness. Int. J. Adv. Robot. Syst. 2020, 17, 172988142090781. [CrossRef]

19. Cruz Ulloa, C.; Terrile, S.; Barrientos, A. Soft Underwater Robot Actuated by Shape-Memory Alloys "JellyRobcib" for Path Tracking through Fuzzy Visual Control. Appl. Sci. 2020, 10, 7160. [CrossRef]

20. Ashuri, T.; Armani, A.; Jalilzadeh Hamidi, R.; Reasnor, T.; Ahmadi, S.; Iqbal, K. Biomedical soft robots: Current status and perspective. Biomed. Eng. Lett. 2020, 10, 369-385. [CrossRef] [PubMed]

21. Romanò, J.; Lazzari, F.; Garavaglia, L.; Pittaccio, S. Alternative design strategy and multi-material integration in the development of biologically-inspired soft robots: A proof-of-concept. Smart Mater. Struct. 2020, 29, 125016. [CrossRef]

22. Copaci, D.-S.; Blanco, D.; Martin-Clemente, A.; Moreno, L. Flexible shape memory alloy actuators for soft robotics: Modelling and control. Int. J. Adv. Robot. Syst. 2020, 17, 172988141988674. [CrossRef]

23. Motzki, P.; Khelfa, F.; Zimmer, L.; Schmidt, M.; Seelecke, S. Design and Validation of a Reconfigurable Robotic End-Effector Based on Shape Memory Alloys. IEEE/ASME Trans. Mechatron. 2019, 24, 293-303. [CrossRef]

24. Motzki, P.; Seelecke, S.; Rizzello, G. A Shape Memory Alloy Smart Handling System for Advanced Manufacturing Applications. In Proceedings of the 2020 7th International Conference on Control, Decision and Information Technologies (CoDIT), Prague, Czech Republic, 29 June-2 July 2020; IEEE: New York, NY, USA, 2020; pp. 229-234, ISBN 978-1-7281-5953-9.

25. Pagel, K. Entwicklung von Formgedächtnisaktoren mit inhärenter Führungsfunktion; Verlag Wissenschaftliche Scripten: Auerbach, Germany, 2018; ISBN 978-3-95735-094-7.

26. Seelecke, S. Sensing Properties of SMA Actuators and Sensorless Control. In Shape Memory Alloy Valves; Czechowicz, A., Langbein, S., Eds.; Springer International Publishing: Cham, Switzerland, 2015; pp. 73-87. ISBN 978-3-319-19080-8.

27. Elahinia, M.H. Shape Memory Alloy Actuators. Design, Fabrication, and Experimental Evaluation; Wiley: Chichester, UK, 2016; ISBN 978-1-118-35944-0.

28. Schiedeck, F. Entwicklung eines Modells für Formgedächtnisaktoren im Geregelten Dynamischen Betrieb. Ph.D. Thesis, Zugl.: Hannover, Univ., PZH Produktionstechn, Zentrum, Garbsen, Germany, 2009.

29. Pagel, K.; Drossel, W.-G.; Zorn, W.; Bucht, A.; Kunze, H. Adaptive Control Concept for Shape Memory Alloy Actuators. In Volume 1: Development and Characterization of Multifunctional Materials; Modeling, Simulation and Control of Adaptive Systems; Integrated System Design and Implementation, Proceedings of the ASME 2013 Conference on Smart Materials, Adaptive Structures and Intelligent Systems, Snowbird, UT, USA, 16-18 September 2013; American Society of Mechanical Engineers: New York, NY, USA, 2013; ISBN 978-0-7918-5603-1.

30. Pollmann, J.; Meier, H.; Kuhlenkötter, B. Modular Desktop Machining Centre with SMA Actuation. In Small Machine Tools for Small Workpieces; Wulfsberg, J.P., Sanders, A., Eds.; Springer International Publishing: Cham, Switzerland, 2017 ; pp. 117-130. ISBN 978-3-319-49267-4.

31. Manfredi, L.; Cuschieri, A. Design of a 2 DOFs Mini Hollow Joint Actuated with SMA Wires. Materials (Basel) 2018, 11, 2014. [CrossRef] [PubMed]

32. Manfredi, L.; Huan, Y.; Cuschieri, A. Low power consumption mini rotary actuator with SMA wires. Smart Mater. Struct. 2017, 26, 115003. [CrossRef]

33. Duering, T.W.; Pelton, A.R. TiNi Shape Memory Alloys. Adv. Mater. 1994, 1035-1048.

34. Eggeler, G.; Hornbogen, E.; Yawny, A.; Heckmann, A.; Wagner, M. Structural and functional fatigue of NiTi shape memory alloys. Mater. Sci. Eng. A 2004, 378, 24-33. [CrossRef]

35. Theren, B.; Otibar, D.; Weirich, A.; Brandenburg, J.; Kuhlenkötter, B. Methodology for Minimizing Operational Influences of the Test Rig During Long-Term Investigations of SMA Wires. In Proceedings of the ASME 2019 Conference on Smart Materials, Adaptive Structures and Intelligent Systems, Louisville, KY, USA, 9-11 September 2019; American Society of Mechanical Engineers: New York, NY, USA, 2019. ISBN 978-0-7918-5913-1.

36. Hornbogen; Schmitt. Legierungen mit Formgedächtnis; VS Verlag für Sozialwissenschaften: Opladen, Germany, 1991; ISBN 3531083880.

37. Fleczok, B.; Rathmann, C.; Otibar, D.; Weirich, A.; Kuhlenkötter, B. Impact of Different Electrical Time-Based Activations on NiTi Shape Memory Alloys. IOP Conf. Ser. Mater. Sci. Eng. 2017, 216, 12008. [CrossRef]

38. Feldhusen, J.; Grote, K.-H. Pahl/Beitz Konstruktionslehre; Springer: Berlin/Heidelberg, Germany, 2013; ISBN 978-3-642-29568-3.

39. Roddeck, W. Einführung in die Mechatronik, 6; überarb. u. erw. Auflage 2020; Springer Fachmedien Wiesbaden GmbH: Wiesbaden, Germany, 2019; ISBN 978-3-658-27774-1. 